\title{
A Robust Logic for Rule-based Reasoning under Uncertainty
}

\author{
Simon Parsons ${ }^{\dagger}$, Miroslav Kubat* ${ }^{*}$, and Mirko Dohnal $§$ \\ $\dagger$ Department of Electronic Engineering, Queen Mary and Westfield College, Mile End Road, \\ London, E1 4NS, United Kingdom. \\ *Computer Centre, Technical University of Brno, Udolni 19, 60200 Brno, Czechoslovakia. \\ §Advanced Computation Laboratory, Imperial Cancer Research Fund, Lincoln's Inn Fields, \\ London WC2A 3PX, United Kingdom.
}

\begin{abstract}
Reasoning with uncertain information is a problem of key importance when dealing with real knowledge. The more information required by the procedure used to handle the knowledge, the higher the probability of failure of the reasoning system. The theory of rough sets is not information intensive and is thus a good basis for reasoning in domains where knowledge is sparse. We present a logic based on rough set theory that is suitable for reasoning under uncertainty, a rough inference rule, and demonstrate its effectiveness in rule-based reasoning.
\end{abstract}

\section{Introduction}

Any system designed to reason about the real world must be capable of dealing with uncertain information. This is a consequence of the complexity of the real world and the finite size of the knowledge base that such a system has at its disposal. A number of mathematical formalisms have been developed to cope with uncertainty in knowledgebased systems [4]. These formalisms all suffer from the fact that they are information intensive, requiring large amounts of precise information in order to deal with uncertainty. Thus truth values of relations between variables are required in the form of grades of membership and probability distributions. Such values are often unknown, or expensive to obtain, and methods that are not information intensive are often desirable.

\section{Rough set theory}

Consider a set of elementary objects $\mathbf{A}=\left\{\mathrm{A}_{1}, \ldots, \mathrm{A}_{\mathrm{n}}\right\}$. The members of this set are used to define a set of objects $\mathbf{E}=\left\{\mathrm{E}_{1}, \ldots, \mathrm{E}_{\mathrm{m}}\right\}$ each of the $\mathrm{A}_{\mathrm{i}}$ corresponding to $\mathrm{a}$ possible attribute of the $E_{j}$. Since the specification of the $E_{j}$ must be based on the $A_{i}$ alone, it could well be the case that some of the specifications of the $E_{j}$ are indistinguishable since the values that distinguish them are not identified by the $\mathrm{A}_{\mathrm{i}}$. Thus the use of a finite set $\mathbf{A}$ implies the existence of an equivalence relation and a consequent partition on $\mathbf{E} ; \mathbf{P}=\left\{\mathrm{P}_{1}, \ldots, \mathrm{P}_{\mathrm{r}}\right\}$ where $\cup \mathrm{P}_{\mathrm{i}}=$ $\mathbf{E}$ and $\mathrm{P}_{\mathrm{i}} \mathrm{fiP}_{\mathrm{j}}=\varnothing$ for $\mathrm{i} \neq \mathrm{j}=1, \ldots, \mathrm{r}$ and each $\mathbf{P}_{\mathrm{S}}=$ $\left(\mathrm{E}_{\mathrm{S}_{1}}, \ldots, \mathrm{E}_{\mathrm{Z}_{\mathrm{s}}}\right)$ is an equivalence class. Let $\mathrm{T}<\mathbf{S}$ be an object, whose attributes are $\mathrm{T}_{\mathrm{A}} / \mathbf{A}$, that we wish to describe in terms of the set of partitioned attributes $\mathrm{E}_{\mathrm{i}}$.

$$
\begin{array}{lll}
\mathrm{T}^{\mathrm{c}}(\mathbf{P}, \mathbf{E}) & = & \left\{\mathrm{e}: \mathrm{e} \in \mathrm{P}_{\mathrm{i}}, \mathrm{P}_{\mathrm{i}}<\mathrm{T} \neq \varnothing\right\} \\
\mathrm{T}^{\mathrm{e}}(\mathbf{P}, \mathbf{E}) & = & \left\{\mathrm{e}: \mathrm{e} \in \mathrm{P}_{\mathrm{i}}, \mathrm{P}_{\mathrm{i}} \mathrm{fiT} \neq \varnothing\right\}
\end{array}
$$

where $\mathrm{T}^{\mathrm{c}}(\mathbf{P}, \mathbf{E})$ is the core of $\mathrm{T}$ based on $\mathbf{E}$ and $\mathbf{P}$, and $\mathrm{T}^{\mathrm{e}}(\mathbf{P}, \mathbf{E})$ is the envelope. The pair $\left[\mathrm{T}^{\mathrm{c}}(\mathbf{P}, \mathbf{E}), \mathrm{T}^{\mathrm{e}}(\mathbf{P}, \mathbf{E})\right]$ is a rough set [3].

We can determine the degree to which logical combinations of roughly defined objects may themselves be defined. Logical operations such as disjunction, implication and negation may be defined in terms of set operations on the core and envelope of the objects concerned:

$$
\begin{array}{llllll}
(\mathrm{A} \vee \mathrm{B})^{\mathrm{c}} & \mathrm{a} & \mathrm{A}^{\mathrm{c}} f \mathrm{~B}^{\mathrm{c}} & (\mathrm{A} \wedge \mathrm{B})^{\mathrm{c}}=\mathrm{A}^{\mathrm{c}} f \mathrm{~B}^{\mathrm{c}} \\
(\mathrm{A} \vee \mathrm{B})^{\mathrm{e}}=\mathrm{A}^{\mathrm{e}} f \mathrm{~B}^{\mathrm{e}} & (\mathrm{A} \wedge \mathrm{B})^{\mathrm{e}} / \mathrm{A}^{\mathrm{e}} f \mathrm{~B}^{\mathrm{e}} \\
(\neg \mathrm{A})^{\mathrm{c}}=\sim\left(\mathrm{A}^{\mathrm{e}}\right) & (\mathrm{A} \rightarrow \mathrm{B})^{\mathrm{c}} & \mathrm{a} & \sim \mathrm{A}^{\mathrm{e}} f \mathrm{~B}^{\mathrm{c}} \\
(\neg \mathrm{A})^{\mathrm{e}}=\sim\left(\mathrm{A}^{\mathrm{c}}\right) & (\mathrm{A} \rightarrow \mathrm{B})^{\mathrm{e}}= & \sim \mathrm{A}^{\mathrm{c}} f \mathrm{~B}^{\mathrm{e}}
\end{array}
$$

where $\sim \mathrm{A}$ is the complement of set $\mathrm{A}$.

\section{A logic of rough truth values}

Consider a Boolean algebra of propositions $(\mathrm{P}, \mathrm{\vee}, \wedge$, ᄀ). We define a rough measure $R$ on $P$ such that $p \in P$, $R(p)=\left[p^{c}, p^{e}\right] . R(p)$ may be related to the truth of the proposition $p$ by careful choice of the set $\mathbf{A}$ [2]. We can distinguish the following limiting values of $R(p)$, for $\varnothing<\mathrm{X}<\mathbf{A}$, and $\varnothing<\mathrm{Y}<\mathbf{A}$, which form a lattice, ordered by set inclusion:

$$
\begin{gathered}
{[\varnothing, \varnothing] /[\varnothing, \mathrm{X}] /} \\
\text { false }
\end{gathered}
$$

We then introduce a rough truth measure $R V$ which identifies which of these five values each $\mathrm{p} \in \mathrm{P}$ takes on. 
The advantages of such a measure are its extreme simplicity and robustness. The logical behaviour of the measure RV is established from set operations on the measure $\mathrm{R}$ for relevant propositions. For example:

$$
\mathrm{RV}(\mathrm{p} £ \mathrm{q}) \quad=\quad \max (\mathrm{RV}(\mathrm{p}), \mathrm{RV}(\mathrm{q}))
$$

We can adapt reasoning patterns of classical logic such as modus ponens for this rough valued logic:

$$
\alpha \geq \begin{array}{lll}
\operatorname{RV}(p \rightarrow q) & = & \alpha \\
\operatorname{RV}(p)= & \beta & \\
(q) \geq & \min (\alpha, \beta)
\end{array}
$$

\section{An example}

Consider the following simple example, based on the 'meeting problem' [1], from which we can deduce two conflicting results:

C1. If Robert comes to a meeting, then Mary does not come. $\mathrm{R}(\mathrm{x}) \rightarrow \neg \mathrm{M}(\mathrm{x})(\mathrm{t})$.

$\mathrm{C} 2$. Robert is coming to the meeting tomorrow. $\mathrm{R}(\mathrm{m})(\mathrm{t})$.

C3. If Beatrix comes to the meeting tomorrow, it is unlikely to be quiet. $\mathrm{B}(\mathrm{m}) \rightarrow \neg$ quiet $(\mathrm{m})$ (rt).

$\mathrm{C} 4$. Beatrix may come to the meeting tomorrow. $\mathrm{B}(\mathrm{m})(\mathrm{rf})$.

C5. If Albert comes to a meeting, then it is almost certain that the meeting will be quiet. $\mathrm{A}(\mathrm{x}) \rightarrow$ quiet $(\mathrm{x})(\mathrm{rt})$.

C6. If MAry does not come to a meeting, then John almost definitely comes. $\neg \mathrm{M}(\mathrm{x}) \rightarrow \mathrm{J}(\mathrm{x})$ (rt).

C7. If John comes to the meeting tomorrow, it is rather likely that Albert will come. $\mathrm{J}(\mathrm{m}) \rightarrow \mathrm{A}(\mathrm{m})(\mathrm{rt})$.

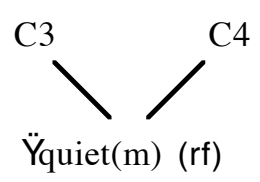

Since quiet $(m)$ is deduced with value rt, a higher truth value than that with which the conclusion Yquiet(m) is reached, we can conclude that the meeting is very likely to be quiet.

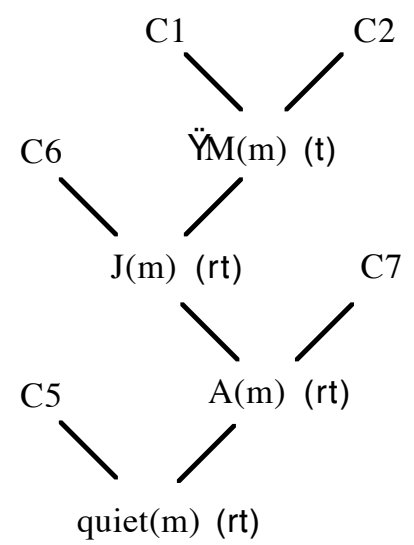

\section{Rule-based reasoning}

In many domains detailed numerical estimates of the certainty of rules and facts may be impossible to obtain, and the inference mechanism adopted must be capable of dealing with vague estimates.

The knowledge base of a typical rule-based system consists of a series of rules of the form 'if $p$ then q' with a certainty value attached to each. In forward chaining inference starts with one or more facts, also with an associated certainty, which match the antecedents of particular rules. These rules are fired to obtain their consequents, with the certainty of the consequent being determined by a combination of the certainties of rule and antecedent, and the consequents used to fire more rules.

If we assume that rules of the form 'if $p$ then $q$ ' are translated by use of material implication into logical statements of the form $\mathrm{p} \rightarrow \mathrm{q}$, then the mechanism of forward chaining is the modus ponens. We can establish when consequent values of unknown certainty will be generated, taking the lower bound on the value of q:
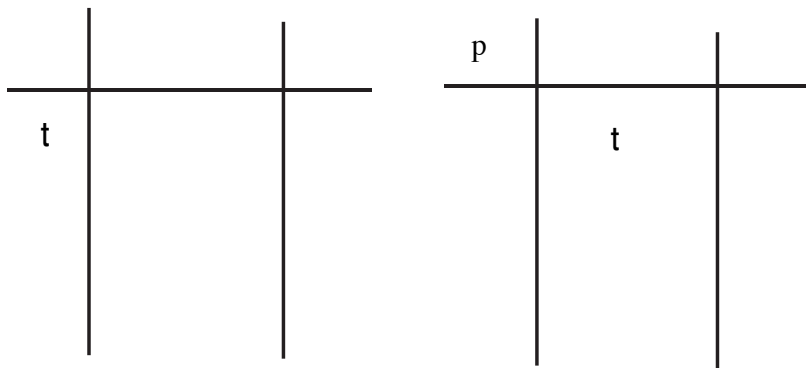

No combinations of values of antecedent and rule other than those shown, have either antecedent, consequent, or rule valued as unknown. The truth tables show that the value of the consequent can be determined if the value of the rule and the antecedent is not unknown, or, if one has an unknown value the other has the value false (f) or roughly false (rf). Thus the logic has the ability to absorb vague data.

\section{Conclusion}

We have presented a symbolically quantified logic for reasoning under uncertainty that is based upon the concept of rough sets. This mathematical model provides a simple yet sound basis for a robust reasoning system. We have supplied a rule of inference analogous to modus ponens, and shown how it might be used by a reasoning system to determine the most likely outcome under conditions of uncertain knowledge. An analysis of the robustness of the logic in rule-based reasoning has also been presented.

\section{References}

[1] Dubois D., Lang J., Prade H. Theorem proving under uncertainty - a possibility based approach. Proceedings of the 10th Joint Conference on Artificial Intelligence, Milan, 984-986 1987.

[2] Parsons, S., Kubat, M. and Dohnal, M. A rough set approach to reasoning under uncertainty, Technical Report, Dept. Electronic Engineering, Queen Mary and Westfield College, 1991.

[3] Pawlak, Z. Rough Sets, International Journal of Information and Computer Sciences, 11, 341-356, 1982.

[4] Saffiotti, A. An AI view of the treatment of uncertainty. The Knowledge Engineering Review, 2, 75-97 1987. 